\title{
Comparison between the first-line and second-line immunotherapy drugs in the progression-free survival and overall survival in advanced non-small cell lung cancer: a systematic review and meta-analysis of randomized controlled trials
}

\author{
Shengyu Wu ${ }^{1,2}$, Lei Wang ${ }^{1,2}$, Wei Li $^{1,2}$, Bin Chen ${ }^{1,2}$, Yu Liu ${ }^{1,2}$, Hao Wang ${ }^{1,2}$, Sha Zhao ${ }^{1,2}$, Lingyun Ye ${ }^{1,2}$, \\ Hui Sun ${ }^{1,2}$, Yayi $\mathrm{He}^{1}$ \\ ${ }^{1}$ Department of Medical Oncology, Shanghai Pulmonary Hospital, Tongji University Medical School Cancer Institute, Tongji University School of \\ Medicine, Shanghai, China; ${ }^{2}$ Tongji University, Shanghai, China \\ Contributions: (I) Conception and design: S Wu, Y He, H Sun; (II) Administrative support: Y He, H Sun; (III) Provision of study materials or patients: \\ L Wang, W Li; (IV) Collection and assembly of data: L Wang, W Li; (V) Data analysis and interpretation: B Chen, S Wu; (VI) Manuscript writing: \\ All authors; (VII) Final approval of manuscript: All authors. \\ Correspondence to: Yayi He. Department of Medical Oncology, Shanghai Pulmonary Hospital, Tongji University Medical School Cancer Institute, \\ Tongji University School of Medicine, No 507 Zhengmin Road, Shanghai 200433, China. Email: 2250601@qq.com; Hui Sun. Department of \\ Medical Oncology, Shanghai Pulmonary Hospital, Tongji University Medical School Cancer Institute, Tongji University School of Medicine, No \\ 507 Zhengmin Road, Shanghai 200433, China; Tongji University, No 1239 Siping Road, Shanghai 200433, China. Email: sunhui2018@163.com.
}

\begin{abstract}
Backgroundk Non-small cell lung cancer (NSCLC) accounts for the majority of lung cancer but with a low early diagnosis rate. With immunotherapy becomes popular in lung cancer, single immunotherapy drug treatment as the first-line or second-line plays an important role. The meta-analysis compares different clinical effects of them by overall survival (OS) and progression-free survival (PFS) because it is important to detect the best time of immunotherapy for NSCLC patients.

Methods: Randomized controlled trials (RCTs) were selected by using the Cochrane Library, Embase, PubMed and Web of science. Pool the hazard ratio (HR) and use the PFS, OS as outcomes.

Results: Ten RCTs were included. The pooled results indicated that first-line and second-line single immunotherapy drug treatment seems to have a tiny difference in PFS, with HR 0.79, 95\% confidence interval (CI): $0.51-1.21, \mathrm{I}^{2}=89 \%$ in first-line single immunotherapy drug treatment and HR $0.74,95 \%$ CI: $0.62-0.89, \mathrm{I}^{2}=84 \%$ in second-line single immunotherapy drug treatment. When it comes to OS, first-line immunotherapy drug treatment still has better effects than the second-line. In first-line single immunotherapy drug treatment, HR $0.78,95 \%$ CI: $0.55-1.11, \mathrm{I}^{2}=83 \%$, but in second-line, HR $0.70,95 \%$ CI: $0.64-0.76, \mathrm{I}^{2}=53 \%$.
\end{abstract}

Conclusions: First-line single drug immunotherapy had the tendency better than single immunotherapy drugs used in second-line treatment.

Koywords: Non-small cell lung cancer (NSCLC); immunotherapy; first-line and second-line; overall survival (OS); randomized controlled trials (RCTs)

Submitted Feb 19, 2020. Accepted for publication Oct 25, 2020.

doi: 10.21037/apm-20-449

View this article at: http://dx.doi.org/10.21037/apm-20-449 


\section{Introduction}

As a malignancy with the highest death rate (1), lung cancer has two major histological types called small cell lung cancer (SCLC) and non-small cell lung cancer (NSCLC) (2). Among them, NSCLC accounts for the majority (3). Different from the high prevalence rate of NSCLC, the early diagnosis rate is fairly low (4). In particular, more than two-thirds of cases can only be diagnosed at an advanced stage in clinical $(2,5)$. In this case, traditional treatment like surgery and chemotherapy cannot get a good result (6). Thus, we try to seek new ways to solve this problem. With the deepening understanding of the immunotherapy, it is therefore applied to tumor therapy and change the treatment ideas, NSCLC included (2,7-9).

At present, first-line immunotherapy in NSCLC is mainly focused on combination immunotherapy, for example, the combination of immunotherapy and targeted agents and so on (10-15). Meanwhile, the single immunotherapy drug treatment also shows its powerful role. The study is mainly focused on the efficacy of antiprogrammed death receptor-1 (PD-L1) monoclonal antibodies, such as nivolumab, pembrolizumab and atezolizumab in NSCLC patients (16-19).

Single immunotherapy drug treatment was proved to be essential in second-line immunotherapy as well, including pembrolizumab, nivolumab, atezolizumab, and durvalumab (20-25). Different from first-line immunotherapy, secondline immunotherapy mostly just use a single drug instead of combination therapy $(23,26-28)$.

Because there is still no paper referred to the comparison between the clinical effect of first-line and second-line immunotherapy drug treatment of NSCLC, our metaanalysis will overcome this deficiency. In this article, we use overall survival (OS) and progression-free survival (PFS) to compare the clinical effect of these two kinds of immunotherapy drugs.

We present the following article in accordance with the PRISMA reporting checklist (available at http://dx.doi. org/10.21037/apm-20-449).

\section{Methods}

\section{Literature search}

A comprehensive and systematic literature search was carried out in the Cochrane Library (https://www. thecochranelibrary.com.), Embase ("https://www.embase. com.), PubMed (http://www.ncbi.nlm.nih.gov/pubmed.) and Web of Science (http://isiknowledge.com.) (up to November 2019) to find the relevant literature. Keywords such as non-small cell lung cancer, immunotherapy, firstline treatment, second-line treatment and so on were used and there was no time or region limit.

\section{Article selection and extraction}

Initially, after reading the title, articles differing from the standard were eliminated. Soon afterward, the full text should be scanned and evaluation was made if the previous step could not determine whether it is suitable for inclusion, thus the unrelated one was removed. In the process of screening, two investigators participated and when any difference happens, the negotiation was carried out to ensure consistency.

The inclusion criteria of this study were shown as follows: at first, we choose literature related to the randomized controlled trial (RCT), then those which include OS and PFS were left to evaluate the effect and safety of the firstline and second-line immunotherapy drugs in NSCLC.

Meanwhile, studies were excluded if they were review articles, conference abstracts, quality of the life studies, commentaries, editorials, cost-effectiveness analyses because of their low evidence level. Besides, when there were multiple articles about the same study, the latest and most comprehensive one should be selected by discussion and negotiation. Besides, as we just try to seek the difference in OS and PFS by using the first-line and second-line immunotherapy drugs, combination therapy would be left out.

\section{Quality evaluation}

According to a simple evaluation method in Cochrane Handbook (version 6.0) (https://training.cochrane.org/ handbook.), the data assessment consists of five aspects: randomize, allocation concealment, blinding, incomplete outcome data, no selective outcome reporting and other sources of bias. We will evaluate articles from the abovementioned aspects to ensure quality.

\section{Data extraction}

We extracted OS and PFS from appropriative randomized controlled trails. Relevant data contain study name, trail design, experimental drug, treatment line, phase, the number of total patients and those using experimental drugs, primary endpoints, secondary endpoints, study 


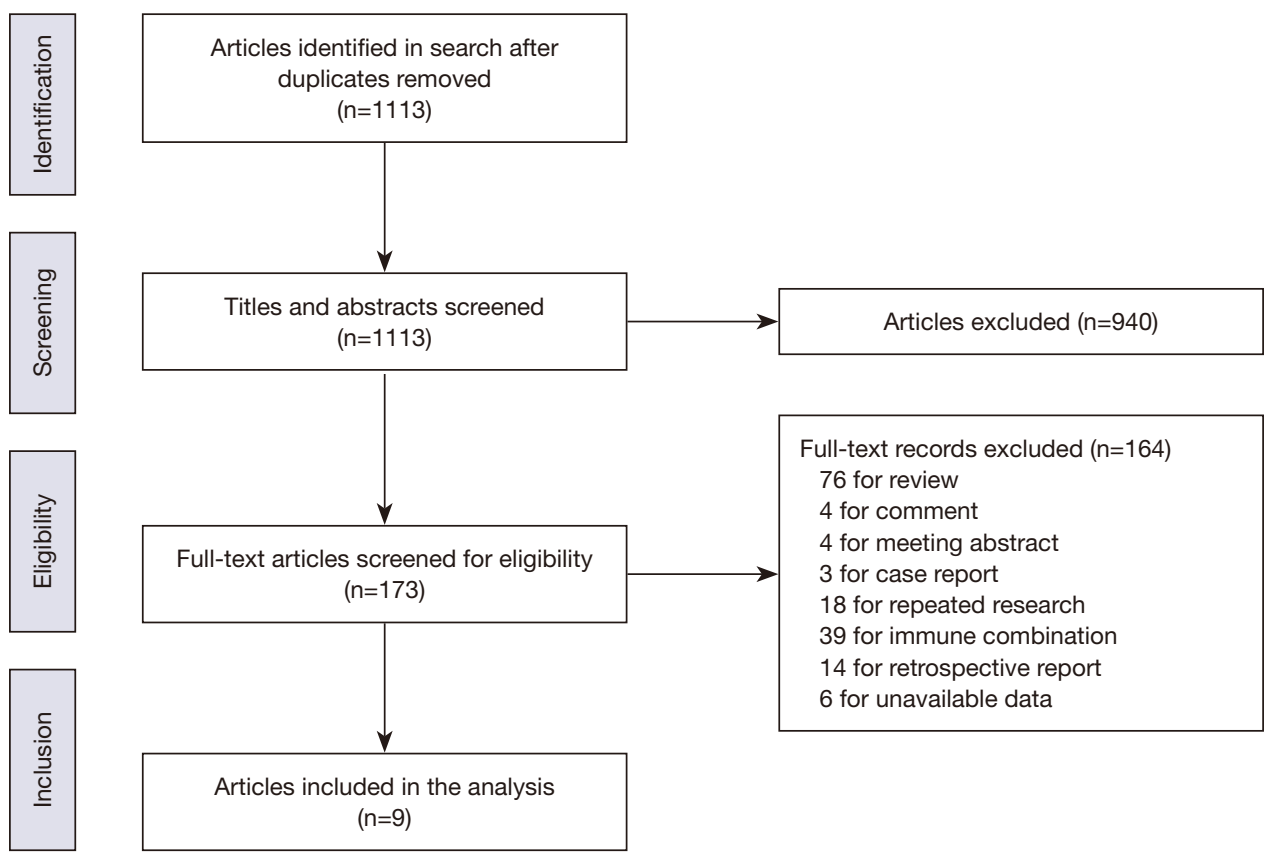

Figure 1 Flow chart. The total process in the meta analysis.

period, national clinical trial (NCT) number, published year and first author.

\section{Statistical analysis}

We analyzed the data by using meta-analysis software RevMan 5.3 (https://community.cochrane.org/help/toolsand-software/revman-5). With PFS and OS viewed as timeto-event outcomes, HR was used to evaluate them and we can easily find HR and both the upper and lower limit of $95 \%$ confidence interval (CI) from articles. Besides, assessing heterogeneity is necessary. If $\mathrm{I}^{2}>75 \%$, then it will be considered as a highly heterogeneous result [35]. As the high heterogeneity in the data we selected, we choose the random-effects model rather than the fixed-effects model. After that, subgroup analyses were conducted to find out whether there are effects and differences to patients by using first-line and second-line immunotherapy drugs. Explore the cause of heterogeneity is another reason for subgroup analyses.

\section{Results}

\section{Selection of qualified studies}

A total of 1,113 related kinds of literature were included after searching all databases and exclusion of literature with repetitive content; After screening titles and abstracts, 940 irrelevant ones were removed; By retaining articles like the review, comment, meeting abstract and others which do not relate to RCTs, 9 articles including 10 studies met our requirements. The flowchart was shown in Figure 1.

\section{Characteristics, outcomes and quality assessment}

We included the RCTs with at least one-year follow-up, the characteristics of them were summed up in Table 1. The outcomes (OS, PFS) were in Table 2. All drugs which are single used for treatment in the trials were divided into two groups, the first-line single immunotherapy drug treatment and the second-line single immunotherapy drug treatment. According to the Cochrane Handbook, systematic reviews about the data extracted were conducted in Table 3.

\section{PFS}

At first, we selected 10 trials in all and divided them into two groups. The pooled results indicated that first-line and second-line single immunotherapy drug treatment have differences, with a hazard ratio (HR) $0.79,95 \%$ CI: 0.51-1.21, $\mathrm{I}^{2}=89 \%$ in first-line single immunotherapy drug treatment and HR $0.74,95 \%$ CI: $0.62-0.89, \mathrm{I}^{2}=84 \%$ in second-line 


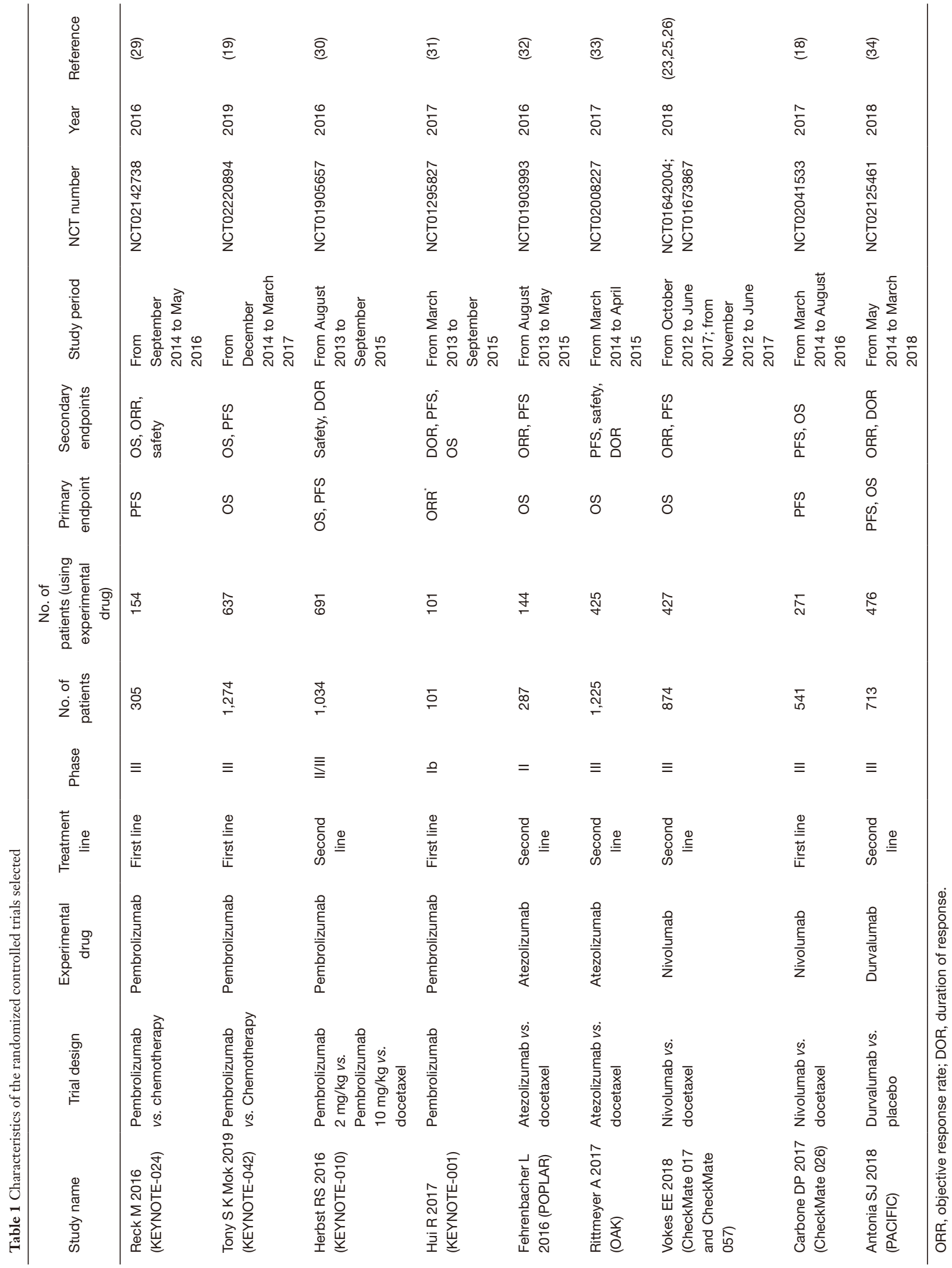


Table 2 Outcomes of the randomized controlled trials selected

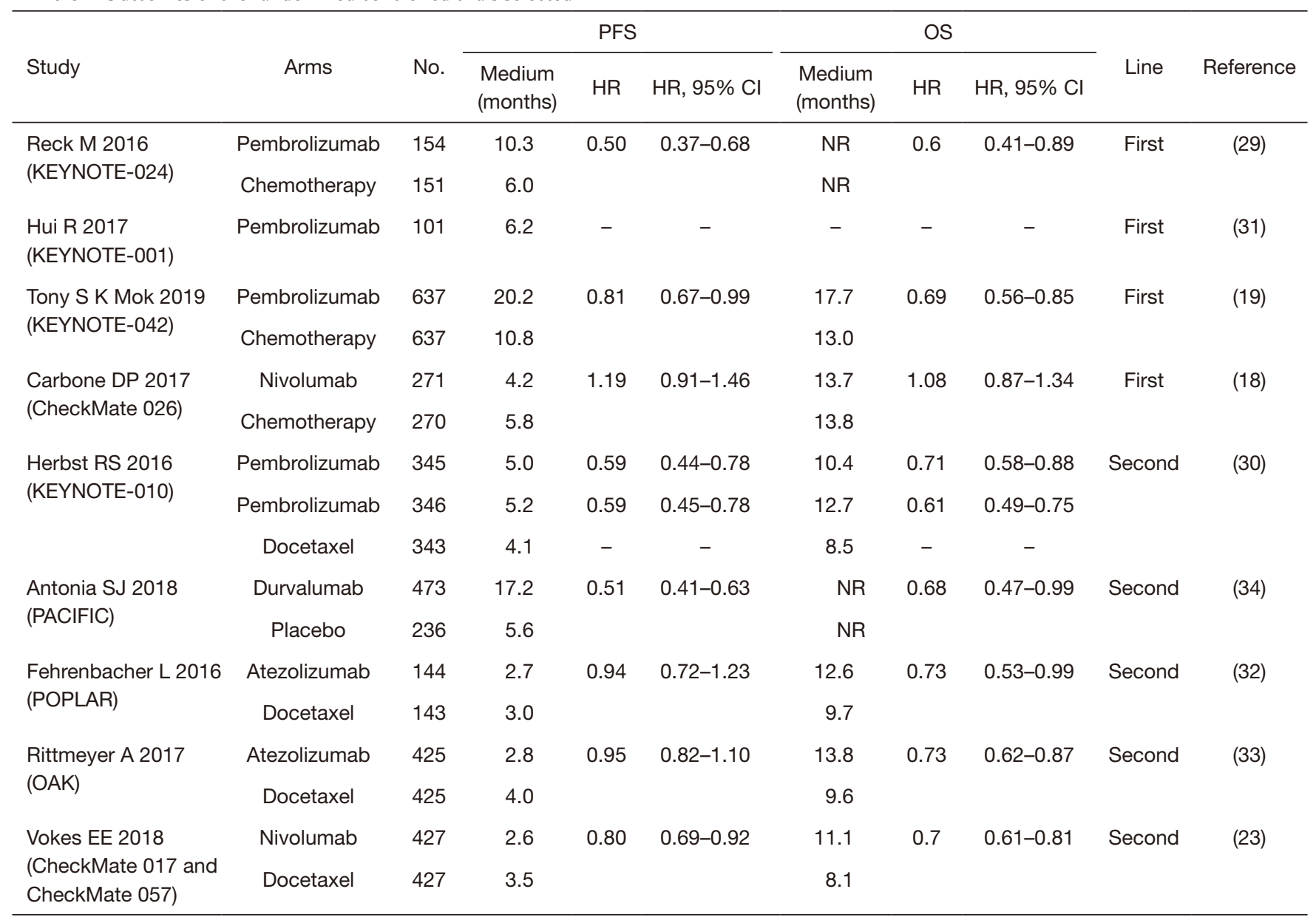

NR, not reach.

Table 3 Outcomes of the randomized controlled trials selected

\begin{tabular}{|c|c|c|c|c|c|c|c|}
\hline Study & $A^{*}$ & $\mathrm{~B}^{*}$ & $\mathrm{C}^{*}$ & $D^{*}$ & $\mathrm{E}^{*}$ & $\mathrm{~F}^{*}$ & Total \\
\hline Herbst RS 2016 (KEYNOTE-010) & $Y^{*}$ & $Y^{*}$ & - & - & $Y^{*}$ & $Y^{*}$ & 4 \\
\hline Reck M 2016 (KEYNOTE-024) & $Y^{*}$ & $Y^{*}$ & $Y^{*}$ & - & $Y^{*}$ & $Y^{*}$ & 5 \\
\hline Tony S K Mok 2019 (KEYNOTE-042) & $Y^{*}$ & - & $Y^{*}$ & $Y^{*}$ & $Y^{*}$ & $Y^{*}$ & 5 \\
\hline Vokes EE 2018 (CheckMate 017 and CheckMate 057) & $Y^{*}$ & $Y^{*}$ & - & $Y^{*}$ & $Y^{*}$ & $Y^{*}$ & 5 \\
\hline Fehrenbacher L 2016 (POPLAR) & $Y^{*}$ & $Y^{*}$ & - & - & $Y^{*}$ & - & 3 \\
\hline Rittmeyer A 2017 (OAK) & $Y^{*}$ & - & $Y^{*}$ & - & $Y^{*}$ & $Y^{*}$ & 4 \\
\hline Antonia SJ 2018 (PACIFIC) & $Y^{*}$ & - & $Y^{*}$ & - & - & $Y^{*}$ & 3 \\
\hline
\end{tabular}

The outcomes of KEYNOTE-024, KEYNOTE-042, KEYNOTE-010, KEYNOTE-001, POPLAR, OAK, CheckMate 017/CheckMate 057, CheckMate 026 and PACIFIC clinical trials based on Cochrane Handbook. $A^{*}$ : sequence generation; $B^{*}$ : allocation concealment; $C^{*}$ : blinding; $D^{\star}$ : incomplete outcome data; $E^{\star}$ : no selective outcome reporting; $F^{\star}$ : other sources of bias; $Y^{\star}$ : low risk. 
single immunotherapy drug treatment (Figure 2A). However, we can also see that the heterogeneity is too high in both groups and the data in first-line single immunotherapy drug treatment have no statistical sense as P-value greater than 0.05 , so we next choose the random-effects model and do subgroup analysis and sensitivity analysis. Afterward, in trials about the first-line drugs, we can see that due to the lack of data in HR, the study named KEYNOTE-001 (31) fails to be included and the KEYNOTE-024 trial (29) is the main cause of high heterogeneity (Figure 2B). For the six trials referred to second-line drugs, except PACIFIC study, the rest can be put into the same subgroup with relatively low heterogeneity (Figure 2C). For sensitivity analysis, both of the first-line and second-line drugs show stable results.

\section{OS}

When it comes to OS, first-line immunotherapy drug treatment still has better effects than the second-line. In first-line single immunotherapy drug treatment, HR $0.78,95 \%$ CI: $0.55-1.11, \mathrm{I}^{2}=83 \%$, but in second-line, HR $0.72,95 \%$ CI: $0.65-0.81, \mathrm{I}^{2}=53 \%$. Data in first-line single immunotherapy drug treatment have a high heterogeneity and no statistical sense ( $\mathrm{P}$ value is greater than 0.05 ), this group needs subgroup analysis and sensitivity analysis to find out the reason (Figure 3A). Then, we can find that the high heterogeneity is due to the study CheckMate 026 (18) (Figure 3B). After sensitivity analysis, we can find both the first-line and second-line drugs show stable results.

\section{Publication bias}

A funnel plot is applied to seek if there is any publication bias. However, though we included 10 trials, the study called KEYNOTE-001 lacked relative data. So we just included 9 studies in fact, and using the funnel plot seemed to have no sense due to Cochrane Handbook (https:// training.cochrane.org/handbook).

\section{Discussion}

Our meta-analysis pioneered the comparison between different effects in NSCLC patients by using first-line and second-line single immunotherapy drug treatment. This study can help guide the future direction of immunotherapy. Our analysis demonstrates that the first-line and second-line single immunotherapy drug treatment show both improved PFS and OS in NSCLC, and there are relatively obvious differences in them. The first-line single immunotherapy drug treatment seems to be more efficient.

The available evidence is gotten from 10 RCT. For the results of PFS showed in the forest plot, there is a $5 \%$ difference between the first-line drugs and second-line drugs. Due to the heterogeneity that cannot be ignored in them, we performed further analysis. Evidence shows that KEYNOTE-024 (29) leads to the heterogeneity of PFS in first-line drugs. One reason is that the number of patients in this study is smaller compared with others. Another reason that makes this result worse is that few articles were selected in first-line single immunotherapy drug treatment. Because of few RCT in first-line single drugs, we have to admit that the high heterogeneity is hard to avoid up to now. What's more, lack of tumor proportion score in some trials like KEYNOTE-042 (19), we cannot make sure if the patients recruited were in the same stage, and this may be a huge problem. Because of the clinical heterogeneity, we choose a random-effects model to reduce it. In second-line drugs, the studies POPLAR (32), OAK (33), CheckMate 017 and CheckMate 057 (23) and so on have low heterogeneity, and the PACIFIC leads to high heterogeneity in all. Of course, it may because of our few selected trials, but another reason is that the internal structure about the included patients, for example, age and gender.

First-line single immunotherapy drug treatment has longer OS than the second-line. It is noteworthy that the heterogeneity in the first-line is high. In addition, there is one study in first-line that lacks OS. According to our analysis, CheckMate 026 (18) mainly causes this problem. The situation happened maybe because their first-line drugs are different. In study CheckMate 026 (18), the drug is nivolumab while in studies called KEYNOTE-024 (29) and KEYNOTE-042 (19), the drug is pembrolizumab.

All data shows that single immunotherapy drug treatment is better to use in the first line than in the second line. It indicates that immunotherapy should be used before chemotherapy. First-line treatment in NSCLC may reduce the effect of immunotherapy.

In sum, our meta-analysis still has deficiencies, but it is still the first one trying to make a comparison between the results of first-line and second-line single immunotherapy drug treatment in NSCLC and give us some suggestion for the time of immunotherapy in NSCLC. 

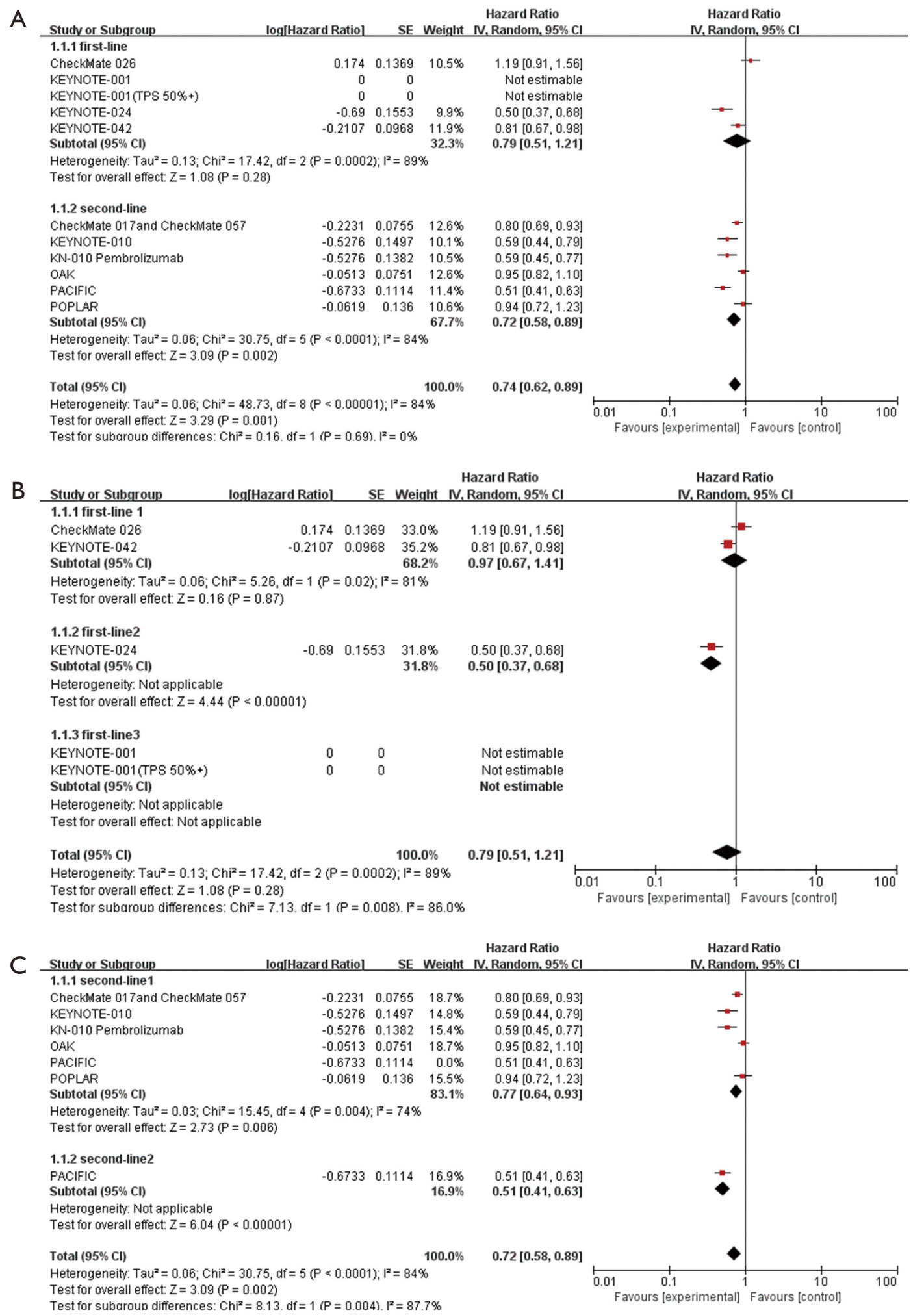

Figure 2 Forest plots for progression-free survival. (A) The comparison of progression-free survival in first-line and second-line single immunotherapy drug treatment (fixed effects model); (B) the comparison of hazard ratio in first-line and second-line single immunotherapy drug treatment (random effects model); (C) subgroup analysis. 


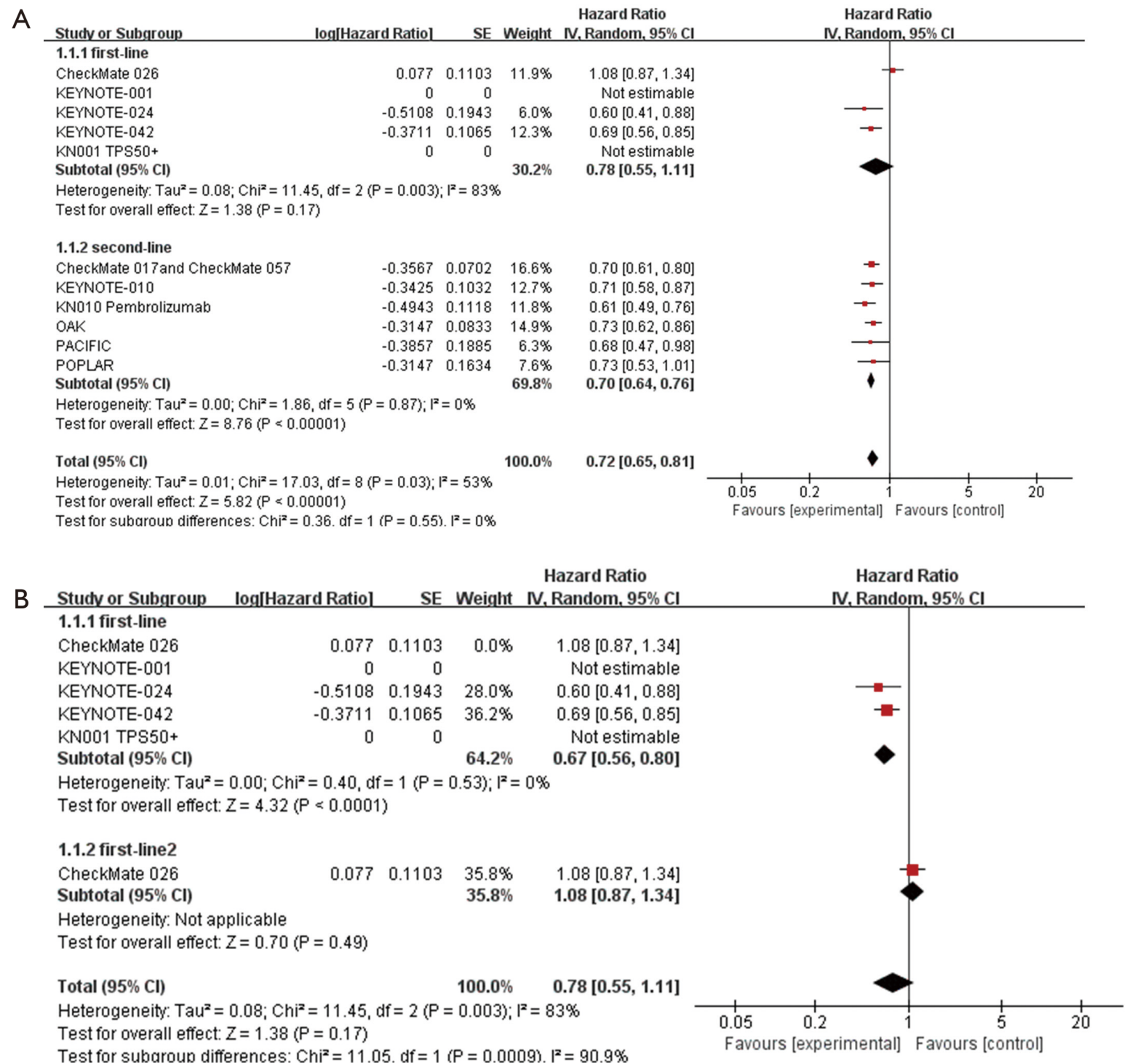

Figure 3 Forest plots for overall survival. (A) The comparison of overall survival in first-line and second-line single immunotherapy drug treatment (fixed effects model); (B) Subgroup analysis.

\section{Acknowledgments}

Funding: This study was supported in part by a grant of young talents in Shanghai, National Natural Science Foundation of China (81802255), Young Talents in Shanghai (2019 QNBJ), 'Dream Tutor' Outstanding Young Talents Program (fkyq1901), Clinical Research Project of Shanghai Pulmonary Hospital (fk18005), Key Discipline in 2019 (oncology), Project of Shanghai Municipal Science and Technology Commission (Project of Municipal Science and Technology Commission), Scientific research project of Shanghai Pulmonary Hospital (fkcx1903), Shanghai Municipal Commission of Health and Family Planning (2017YQ050), Innovation Training Project of SITP of Tongji University, and key projects of leading talent (19411950300).

\section{Footnote}

Reporting Checklist: The authors have completed the PRISMA reporting checklist. Available at http://dx.doi. org/10.21037/apm-20-449 
Conflicts of Interest: All authors have completed the ICMJE uniform disclosure form (available at http://dx.doi. org/10.21037/apm-20-449). The authors have no conflicts of interest to declare.

Ethical Statement: The authors are accountable for all aspects of the work in ensuring that questions related to the accuracy or integrity of any part of the work are appropriately investigated and resolved. This research was approved by the ethics committee of the Shanghai Pulmonary Hospital, Tongji University.

Open Access Statement: This is an Open Access article distributed in accordance with the Creative Commons Attribution-NonCommercial-NoDerivs 4.0 International License (CC BY-NC-ND 4.0), which permits the noncommercial replication and distribution of the article with the strict proviso that no changes or edits are made and the original work is properly cited (including links to both the formal publication through the relevant DOI and the license). See: https://creativecommons.org/licenses/by-nc-nd/4.0/.

\section{References}

1. Siegel RL, Miller KD, Jemal A. Cancer statistics, 2018. CA Cancer J Clin 2018;68:7-30.

2. Osmani L, Askin F, Gabrielson E, et al. Current WHO guidelines and the critical role of immunohistochemical markers in the subclassification of non-small cell lung carcinoma (NSCLC): Moving from targeted therapy to immunotherapy. Semin Cancer Biol 2018;52:103-9.

3. Torre LA, Bray F, Siegel RL, et al. Global cancer statistics, 2012. CA Cancer J Clin 2015;65:87-108.

4. Travis WD, Brambilla E, Burke AP, et al. Introduction to The 2015 World Health Organization Classification of Tumors of the Lung, Pleura, Thymus, and Heart. J Thorac Oncol 2015;10:1240-2.

5. Zhang F, Yin Y, Xu T. Cinobufotalin injection combined with chemotherapy for the treatment of advanced NSCLC in China: A PRISMA-compliant meta-analysis of 29 randomized controlled trials. Medicine (Baltimore) 2019;98:e16969.

6. Tun AM, Thein KZ, Thein WL, et al. Checkpoint inhibitors plus chemotherapy for first-line treatment of advanced non-small cell lung cancer: a systematic review and meta-analysis of randomized controlled trials. Future Sci OA 2019;5:FSO421.

7. Herzberg B, Campo MJ, Gainor JF. Immune Checkpoint
Inhibitors in Non-Small Cell Lung Cancer. Oncologist 2017;22:81-8.

8. Steven A, Fisher SA, Robinson BW. Immunotherapy for lung cancer. Respirology 2016;21:821-33.

9. Rolfo C, Caglevic C, Santarpia M, et al. Immunotherapy in NSCLC: A Promising and Revolutionary Weapon. Adv Exp Med Biol 2017;995:97-125.

10. Proto C, Ferrara R, Signorelli D, et al. Choosing wisely first line immunotherapy in non-small cell lung cancer (NSCLC): what to add and what to leave out. Cancer Treat Rev 2019;75:39-51.

11. Remon J, Besse B, Soria JC. Successes and failures: what did we learn from recent first-line treatment immunotherapy trials in non-small cell lung cancer? BMC Med 2017;15:55.

12. Peng $X, Z$ Zhou Q. First-line Combination Immunotherapy in Advanced Non-small Cell Lung Cancer. Zhongguo Fei Ai Za Zhi 2018;21:924-30.

13. Ryu R, Ward KE. Atezolizumab for the First-Line Treatment of Non-small Cell Lung Cancer (NSCLC): Current Status and Future Prospects. Front Oncol 2018;8:277.

14. Bylicki O, Barazzutti H, Paleiron N, et al. First-Line Treatment of Non-Small-Cell Lung Cancer (NSCLC) with Immune Checkpoint Inhibitors. BioDrugs 2019;33:159-71.

15. Peters S, Reck M, Smit EF, et al. How to Make the Best Use of Immunotherapy as First-Line Treatment for Advanced/ Metastatic Non-Small-Cell Lung Cancer. Ann Oncol 2019.

16. Peters S, Gettinger S, Johnson ML, et al. Phase II Trial of Atezolizumab As First-Line or Subsequent Therapy for Patients With Programmed Death-Ligand 1-Selected Advanced Non-Small-Cell Lung Cancer (BIRCH). J Clin Oncol 2017;35:2781-9.

17. Aguilar EJ, Ricciuti B, Gainor JF, et al. Outcomes to first-line pembrolizumab in patients with non-small-cell lung cancer and very high PD-L1 expression. Ann Oncol 2019;30:1653-9.

18. Carbone DP, Reck M, Paz-Ares L, et al. First-Line Nivolumab in Stage IV or Recurrent Non-Small-Cell Lung Cancer. N Engl J Med 2017;376:2415-26.

19. Mok TSK, Wu YL, Kudaba I, et al. Pembrolizumab versus chemotherapy for previously untreated, PD-L1expressing, locally advanced or metastatic non-small-cell lung cancer (KEYNOTE-042): a randomised, open-label, controlled, phase 3 trial. Lancet 2019;393:1819-30.

20. El Karak F, Gh Haddad F, Eid R, et al. Lung cancer and immunotherapy: a real-life experience from second line 
and beyond. Future Oncol 2019;15:3025-32.

21. Vickers AD, Winfree KB, Cuyun Carter G, et al. Relative efficacy of interventions in the treatment of secondline non-small cell lung cancer: a systematic review and network meta-analysis. BMC Cancer 2019;19:353.

22. Horn L, Spigel DR, Vokes EE, et al. Nivolumab Versus Docetaxel in Previously Treated Patients With Advanced Non-Small-Cell Lung Cancer: Two-Year Outcomes From Two Randomized, Open-Label, Phase III Trials (CheckMate 017 and CheckMate 057). J Clin Oncol 2017;35:3924-33.

23. Vokes EE, Ready N, Felip E, et al. Nivolumab versus docetaxel in previously treated advanced non-small-cell lung cancer (CheckMate 017 and CheckMate 057): 3-year update and outcomes in patients with liver metastases. Ann Oncol 2018;29:959-65.

24. Antonia SJ, Lopez-Martin JA, Bendell J, et al. Nivolumab alone and nivolumab plus ipilimumab in recurrent smallcell lung cancer (CheckMate 032): a multicentre, openlabel, phase 1/2 trial. Lancet Oncol 2016;17:883-95.

25. Borghaei H, Paz-Ares L, Horn L, et al. Nivolumab versus Docetaxel in Advanced Nonsquamous Non-Small-Cell Lung Cancer. N Engl J Med 2015;373:1627-39.

26. Brahmer J, Reckamp KL, Baas P, et al. Nivolumab versus Docetaxel in Advanced Squamous-Cell Non-Small-Cell Lung Cancer. N Engl J Med 2015;373:123-35.

27. Sanmamed MF, Perez-Gracia JL, Schalper KA, et al. Changes in serum interleukin-8 (IL-8) levels reflect and predict response to anti-PD-1 treatment in melanoma and non-small-cell lung cancer patients. Ann Oncol

Cite this article as: $\mathrm{Wu} \mathrm{S}$, Wang L, Li W, Chen B, Liu Y, Wang H, Zhao S, Ye L, Sun H, He Y. Comparison between the first-line and second-line immunotherapy drugs in the progression-free survival and overall survival in advanced nonsmall cell lung cancer: a systematic review and meta-analysis of randomized controlled trials. Ann Palliat Med 2021;10(2):17171726. doi: 10.21037/apm-20-449
2017;28:1988-95.

28. Hellmann MD, Ciuleanu TE, Pluzanski A, et al. Nivolumab plus Ipilimumab in Lung Cancer with a High Tumor Mutational Burden. N Engl J Med 2018;378:2093-104.

29. Reck M, Rodriguez-Abreu D, Robinson AG, et al. Pembrolizumab versus Chemotherapy for PD-L1Positive Non-Small-Cell Lung Cancer. N Engl J Med 2016;375:1823-33.

30. Herbst RS, Baas P, Kim DW, et al. Pembrolizumab versus docetaxel for previously treated, PD-L1-positive, advanced non-small-cell lung cancer (KEYNOTE-010): a randomised controlled trial. Lancet 2016;387:1540-50.

31. Hui R, Garon EB, Goldman JW, et al. Pembrolizumab as first-line therapy for patients with PD-L1-positive advanced non-small cell lung cancer: a phase 1 trial. Ann Oncol 2017;28:874-81.

32. Fehrenbacher L, Spira A, Ballinger M, et al. Atezolizumab versus docetaxel for patients with previously treated non-small-cell lung cancer (POPLAR): a multicentre, open-label, phase 2 randomised controlled trial. Lancet 2016;387:1837-46.

33. Rittmeyer A, Barlesi F, Waterkamp D, et al. Atezolizumab versus docetaxel in patients with previously treated non-small-cell lung cancer (OAK): a phase 3, openlabel, multicentre randomised controlled trial. Lancet 2017;389:255-65.

34. Antonia SJ, Villegas A, Daniel D, et al. Overall Survival with Durvalumab after Chemoradiotherapy in Stage III NSCLC. N Engl J Med 2018;379:2342-50. 